\title{
ROLE OF NONVIABLE PRESERVED CORNEAS IN KERATOPLASTY
}

Panda $\mathbf{A}^{1}$

\section{INTRODUCTION}

Corneal blindness is the second most frequent cause of total blindness in Nepal. ${ }^{1}$ While Medical therapy is helpful for infected eyes, rest can be tackled by corneal grafting. Due to inadequate number of tissue availability, penetrating keratoplasty is not feasible for all in Nepal. Therefore, one has to think about the alternative procedure, where preserved corneas obtained from other countries could be utilised satisfactorily. One such surgery is lamellar keratoplasty.

\section{LAMELLAR KERATOPLASTY}

As the name implies lamellar keratoplasty is a Drocedurc where the desirable size and thickness of the recipient's opaque cornea is removed and replaced by the same size and thickness matched donor corneal tissue.

\section{HISTORY}

History dates back to 1886 when the first successful corneal lamellar graft was done on a young girl with corneal opacity due to chemical injury using the rabbit cornea as a donor with encouraging cosmetic and functional success Thereafter, the procedure is being practiced with human donor material.

\section{TYPES}

Various types of lamellar keratoplasty have been described with different mechanism of actions. The central inlay lamellar keratoplasty is optical whereas the peripheral is mainly responsible for the stem cell re-population as these cells are situated at limbus \& $1 \mathrm{~mm}$ in the peripheral cornea or as a tectonic procedure to strengthen the peripheral cornea with central flattening. The onlay lamellar graft provides a tectonic support \& also negates the irregular astigmatism by flattening the cornea as seen in cases of keratoconus. Keyhole pattern has a composite action. It prevents recurrence by providing a barrier $\&$ also helps optical function as seen in eyes with recurrent plerygium. It also provides stem cell to the diseased cornea

\section{HOW DOES IT HELP ?}

\section{The procedure is helpful}

i) by removal of the partial thickness corneal pathology and replacing by the size and depth matched donor corneal tissue.

ii) by flattening the cone in a case of extensive keratoconus or to improve the vision.

iii) by supplementing healthy stem cells in cases extensive corneal chemical bum and

iv) as a tectonic procedure in extensive \& eccentric

Address for correspondence : $\quad$ Dr. Anita Panda, Professor and Head, Department of Ophthalmology

B.P. Koirala Institute of Health Sciences, Dharan, Nepal.

Fax" 977-25-20251, Email: anitap49@yahoo.com 
corneal lesions where penetrating keratoplasty is not primary a procedure of choice.

\section{ADVANTAGES}

Advantages of lamellar keratoplasty over conventional penetrating keratoplasty includes being an extra ocular procedure. It is devoid of any intraocular complications, a large graft can be performed \& there is minimal chance of rejection. Further, it requires less hospitalisation and less follow up visits. Additionally, as a viable endothelium is not essential for lamellar keratoplasty unlike penetrating keratoplasty, even donor corneas preserved in glycerine can be used effectively. This is more important in developing countries where there is scarcity of donor material due to innumerable reasons. Moreover, if the procedure fails it does not preclude lamellar or penetrating keratoplasty at the later date. Further, this procedure is adequate to combat the corneal pathologies even involving up to Descement's membrane.

\section{WHY LAMELLAR KERATOPLASTY IS NOT FOLLOWED AS A COMMON PRACTICE ?}

Lamellar keratoplasty is time consuming \& requires more Kill. As a result, most corneal surgeons tend to avoid it despite its varied indications. Other pitfalls in the procedure which make it less popular being it's inability to eradicate a pathology involving full thickness of the cornea. However, this procedure is adequate to combaot the corneal pathologies even involving upto Descement's membrane.

\section{SOURCES OF DONOR TISSUE/OR LK}

Sources from which the corneal tissues are obtained for lamellar keratoplasty include

I) Eye ball preserved In moist chamber
II) Media preserved corneoscleral tissue

III) Glycerine preserved corneoscleral tissue

IV) Other sources from which only the limbal tissues are obratned for stem cells transplant include

a. in situ removal of the lenticula from the adaver eye without removing eye ball

b. blood related donor and

c. normal fellow eye

\section{METHODS OF LAMELLAR DISCUSSION}

For obtaining better results dissection procedure can be undertaken by microkeratome, open technique or closed technique. As all the corneal surgeons in developing country may not have access to microkeratome, close technique is preferred over open technique. In order to do this, a small cleavage is made with the help of a cyclodialysis spatula or pauflques knife. With help of a nonreflective coating Desmarre's dissector a complete cleavage can be performed. Further, to identify the proper plane, (more so while performing deep lamellar keratoplasty) to lessen the dissection time to obtain a smooth bed, and to avoid intra-operative perforation, stromal injection of either air viscoelastic or saline have been advocated.

\section{INDICATIONS}

Congenital ${ }^{6-12}$

Limbal dernoid

Corneal dermoid

Annular Dermoid

Extensive dermolipoma

Inflammatory ${ }^{2,13,14}$ Post trachoma

Corneal opacity following ulcer

\section{Degenerative ${ }^{2,15-18}$ Pterygium}

Keratoconus and other deg.

Banshaped keratopathy 


\begin{tabular}{|ll}
\hline Dystrophies $^{2}$ & $\begin{array}{l}\text { Epithelial dystrophies } \\
\text { Granular dystrophy }\end{array}$ \\
Neoplastic & \\
& $\begin{array}{l}\text { Invasive sq. cell carcinoma of } \\
\text { conjunctiva and cornea. }\end{array}$ \\
Traumatic $^{2,22-24}$ & $\begin{array}{l}\text { Multiple corneal foreign bodies. } \\
\text { Chemical burn. }\end{array}$
\end{tabular}

REVOLUTION IN SURGICAL TECHNIQUES

Over the years, a number of procedures have been mentioned and recommended.

\section{SURGICAL REVOLUTION}

\section{A. Inlay L. K}

I. Conventional - Lesions involving central/total cornea

Subtotal (central LK)

- Total (Total cornea upto limbus)

- Circular lamellolamellar sclerokeratoplasty (Large diameter LK) ${ }^{2,22,23}$

II. Segmental - Lesions not involving pupillary area

- Lamellolamellar keratoplasty ${ }^{2}$

- Lamellolamellar sclero keratoplasty

III. Keyhole - Lesions involving both peripheral/pupillary area

- Lamellolamellar keratoplasty

- Lamellolamellar sclero keratoplasty

IV. Annular - Lesions involving only peripheral cornea

- Annular LK

B. Onlay L. K.

- $\quad$ Epikeratoplasty ${ }^{16-18}$

- Stemcell transplant (Lenticule/Annular) ${ }^{24}$

- Keratoepithelioplasty

\section{Others}

- $\quad$ Modified stocker's procedure by forming a double chamber. ${ }^{25}$
- Inlay sclerokeratoplasty as an adjunctive procedure to $\mathrm{P} \mathrm{K}$ (sclerokeratoplasty). ${ }^{26-28}$

\section{SURGICAL STEPS}

\section{Conventional inlay L. K}

The indication of this procedure is for ail types of corneal resions involving the partial thickness of the cornea and central in location.

\section{PROCEDURE}

After the size of the corneal lesion is measured the desired trephine size and the depth are adjusted and the cut is given with pressure over recipient cornea. A small pocket is made with Desmarre's lamellar Dissector by closed technique. The partial thickness cornea is removed \& a thorough wash is given to the recipient bed with BSS to wash out tissue debris or blood clot if any. The donor cornea is obtained by similar technique by fixaing the corneoscleral tissue in a Kings' clamp. The donor corneal button thus obtained is sutured to the recipient bed by 16 interrupted 10-0 monofilament nylon sutures with buried knots.

\section{INLAY MODIFIED SEGMENTAL L. K}

This is indicated when the corneal lesion invades the partial thickness of the cornea but are eccentric in nature and not involving the visual axis.

\section{PROCEDURE}

The surgical steps are similar to inlay lamellar keratoplasty except that the preliminary mark is given either with two trephines of different size or free hand method depending upon the size of Involvement. Similar procedure is also adopted for donor button preparation \& fixed to the recipient bed by 10-0 monofilament nylon interrupted sutures with buried knots. 


\section{INLAY KEYHOLE LAMELLAR KERATOPLASTY}

This technique is indicated when there is involvement of the visual axis along with the peripheral cornea.

\section{PROCEDURE}

Surgical steps consist of a mark of the central area without damaging the pterygium by a special trephine having a step at one side Both the ends of the mark are extended to the limbus and the $0.3 \mathrm{~mm}$ thick corneal tissue along with the pterygium mass is separated and fixed at the medial canthus. Identical size and thickness donor tissue is obtained by similar technique and fixed to the recipient bed with 10-0 monofilament nylon interrupted sutures with buried knots.

\section{ANNULAR L. K}

This is indicated for the lesion involving whole of the peripheral cornea, rest being normal procedure. With the help of two trephines of desired size two marks are given one at limbus and other over cornea. The tissue removal is as per other inlay lemellar keratoplasty. To obtain the donor annular tissue the procedure is exactly same as per recipient.

\section{ONLAY LAMELLAR KERATOPLASTY (EPIKERATOPLASTY)}

This is indicated in cases of keratoconus having no apical scarring. This aids In flattening the cornea thereby reducing irregular astigmatism.

\section{PROCEDURE}

With the help of double trephine having $1 \mathrm{~mm}$ difference in diameter $(7.5 \& 8.5 \mathrm{~mm})$ an annular mark Is applied. The outer cut of the annular mark is $0.3 \mathrm{~mm}$ deep. The inner cut is $0.1 \mathrm{~mm}$ deep. A $0.5 \mathrm{~mm}$ broad annular ring is removed with the help of the pierce Hoskin forceps and curved vannas scissors. Once the ring is removed a pocket is made underneath the outer cut. This is followed by the removal of the central corneal epithelium. A thorough wash is given to wash out any remnant of epithelial debris.

To prepare the lanticule the donor tissue is fixed either in an eye ball stand or Kings clamp depending upon the nature of the tissue whether it is eye ball or corneoscleral tissue. Using a trephine having diameter $0.5 \mathrm{~mm}$ larger than the outer cut of the recipient cornea a $0.3 \mathrm{~mm}$ deep cut is applied. The pocket is made \& a piano refractive lenticule is prepared by closed technique utilising the Dessemare's lamellar dissector. The prepared lenticule is sutured to the epithelial free recipient bed by sixteen interrupted 10-0 monofilament nylon sutures with buried knots.

Inlay Deep L.K with Descemetoendotheliotomy

(Modified slacker's procedure/Double chamber technique)

This procedure is indicated in cases of complicated aphakic or pseudophokic painful bullous keratopathy where opening of the chamber is not desirable.

\section{PROCEDURE}

The surgical steps are exactly similar to conventional inlay lamellar keratoplasty except that the recipient bed left is only formed by Descemet's membrane and endothelium of the recipient. A full thickness and $0.5 \mathrm{~mm}$ large than recipient bed donor corneal button is fixed to the recipient bed with 16, 10-0 monofilament nylon sutures over viscoelastic cushion. Three to four peripheral holes each $1-2 \mathrm{~mm}$ size are made at the Descemet's membrane \& endothelium with the help of a 27 gauze bent needle. Prior to application of last suture.

\section{CONCLUSION}

Lamellar keratoplasty will stay forever for its various advantages is a boon for patients with corneal opacities involving upto Descemet's membrane. Further, as it is not dependant on fresh 
and viable donor tissue it can be performed by any ophthalmologist with corneal surgery training by obtaining the tissue from the established eye banks.

\section{REFERENCES}

1. Foster A, Gilbert CE, Epidemiology of childhood blindness eye. 1992, 6:173-176.

2. Panda A. Lammellolamellar sclerokeratoplasty where do we stand today, Eye. 1999:13:221-225.

3. Archila EA. Deep LK - Dissection of host tissue with intrastromal air injection. Corneal $1985: 3: 217-218$

4 Price FW Air lamellar keratoplasty Corneal surg 1989; 5 240-243.

5. Panda A, Sharma N, Singh R. intralamellar dissection. Cornea, 1099, 19:22-25.

6. Mohan M, Mukharjee G, Panda A. Clinical evaluation and surgical intervention of limbal dermoid. Ind jour Ophthalmol 1981:29:69-73.

7. Panda A, Sharma N, Das G, Ghose S. Surgical management and results in epibulbar dermoids. Indian ophthalmology 1996; PP 276-277.

8. Vrabec MP, Jordan JJ, Lawlor PP. Lamellar keratoplasty performed with a corneal dermoid. Ophthalmic, surg. 1994: 25: 389-91.

9. Golubovic S, Latkovic 2, Horyatic OM. Surgical treatment of largo corneal dermoid, Doc Ophth 1995: 91:25-32.

10. Bunllon C, Durand L. Solid dermoids of the limbus and the cornea. Ophthalmologica 1997:211 (6) :367-72.

11. Kaufman A, Medow N, Phillips R, Zaidman G. Treatment of epibulbar limbal dermoid. Jour paed surg and strabismus. 1999:36:136-40.

12. Richard N, Williass A, Munshi SD. Management of comeal opacification associated with epibulbar choristoma. Br. Jour Ophthalmol 1999, 83:14041405 .

13. Sugita J, Kando J. Deep LK with complete removal of pathological stroma $\mathrm{Br}$, J. Ophthalmol. 1997, $81: 184-188$.

14. Panda A, Bogeshwar LMS, Ray M, Singh Jp, Kumor A. D op LK versus PK for corneal lesions. Cornea 1999; 18:172-5
15. Mohan M. Role of keratoplasty in recurrent pterygium proceeding of sixth Afro-Asian congress of Ophthalmol. 1976, PP1-5.

16. Kaufman $\mathrm{HE}$, Werblin TP. Epikeralophakia for the treatment of keratocunus Am Jour Ophthalmol 1982; 93:343-347.

17. Panda A. Epikeratoplasty for keratoconus. Ophthalmic surg. International . 1994:5:3.

18. Panda A, Sharma N, Angra S.K, Vajpayee RB Long term result of epikeratoplasty. Indian Ophthalmol. Today 1995; PP19-20.

19. Panda A, Sharma N, Sen 5, Ghose S, Titiyal JS, Das GK. Lamello lamellar sclerokeratoplasty in sq. cell carcinoma of cornea and conjunctiva. Indian Ophthal. 1996; PP 278-79.

20. Panda A, Sharma N. Treatment for squamous cell carcinoma of conjunctiva. Ocular surg. International. 1996, 7:42.

21. Panda A, Gharma N, Ghose S, Sen G. Frozen section guided excision and lamel lar keratoplasty for extensive squamous cell carcinoma of conjunctiva \& cornea. Advance Cornea. 1997.

22. Kuckelkorn R, Redbrake C, Schrage NF \& Rein M. Keratoplasty with 11-12 diameter for management of severely chemically burned -.yes Ophthalmology 1993, 90:6830-687.

23. Redbrake C, Buchal V \& Relm M, Keratoplasty with a scleral rim after alkali bum. Kl in Monatsbl Auganheikd 1996, 208:145-151.

24. Dua H S Blanco A A. Allolimbal transplantation in patients with limbal stemcell del. Br. Jour Ophthalmol 1999:83: 414-519.

25. Lowenstein A. Intentional retention of DM during PK. Acta Ophth, 1993: 71:280-282.

26. Panda A, Thakur M. Lamelio penelialing Sclerokeraloplasty for spherical anterior staphyloma. Ocular surg. News International 1995: 20-22.

27. Panda A, Sharma N, Angra SK, Singh R. Sclerokeratoplasty vs PK in ant. staphyloma. Ophthalmic surg Laser 1999, 30:31-36.

28. Panda A, Sharma N, Angra 5K, Singh K. Sclerokeratoplasty vs PK in extensive corneal ulcer. Aust. Jour Ophthalmol. 